\title{
PENGARUH MODERNISASI SISTEM ADMINISTRASI PERPAJAKAN DAN KOMPETENSI PEGAWAI PAJAK TERHADAP KEPUASAN WAJIB PAJAK
}

\author{
Ariel Rembet ${ }^{1}$, Herman Karamoy ${ }^{2}$, Inggriani Elim $^{3}$ \\ 1,2,3 Jurusan Akuntansi, Fakultas Ekonomi dan Bisnis, Universitas Sam Ratulangi, Jln. Kampus Bahu, Manado \\ 95115, Indonesia \\ Email : ariel.rembet.ar@gmail.com
}

\begin{abstract}
Taxpayer satisfaction is very important in forming a positive view of the tax authorities. Starting with satisfaction, the taxpeyer does not feel aggrieved when paying taxes. It is also expected that with this satisfaction, the taxpayer will voluntarity pay taxes. The purpose of this study is to register the tax administration system and the tax competency of tax operators on the manado pratama tax service office. This study uses a quantitative approach, collection methods data is carried out through questionnaires. The sample of this study was 100 respondents, which was accidental sampling. Data analysis using statistical tech niques such as vallyditi test, reliability test for questionnaire. Besides the classic assumption test, multiple linear regression, determination coefficient for proof of hypothesis. The results show that the modernization of tax administration systems and the competence of tax employees simultaneously have a significant effect on taxpayer satisfaction. Partially from the results of tasting the test of modernization of the tax administration system and the competence of tax employees have a significant effect on taxpayaer satisfaction. The results of this study suggest that employees and all parties related to the tax service office manado tax service office must pay attention to the factors of the modern tax administration system and tax employees competence. Quality services from tax employees can make taxes feel comfortable and satisfied to fulfill their obligations to pay taxes.
\end{abstract}

Keywords : Modenization of tax administration system, tax employee competence, taxpayer satisfaction.

\section{PENDAHULUAN}

Kepuasan wajib pajak sesuatu yang penting untuk membentuk pandangan yang positif bagi pegawai. Kepuasan wajib pajak membantu mengurangi tax avoidance dan tax evation yang kerap dilakukan. Ketika merasa puas, dengan sendirinya wajib pajak akan patuh membayar pajak. Dengan begitu penerimaan negara yang berasal dari pajak bisa lebih ditingkatkan (Indra pahala dkk, 2013). Melalui direktorat jendral pajak DJP, pemerintah terus melakukan terobosan untuk meningkatkan penerimaan pajak, langkah yang di ambil adalah melakukan perubahan dibidang perpajakan.

Perubahan administrasi dilaksanakan melalui program modernisasi administrasi perpajakan. "Reformasi perpajakan ini mempunyai tiga tujuan utama, meningkatkan kepatuhan, meningkatkan kepercayaan masyarakat, dan meningkatkan integritas dan produktivitas aparatur pajak."(DJP, 2007). Selain modernisasi sistem administrasi, kompetensi pegawai juga merupakan faktor penting untuk meningkatkan kepuasan."karena pegawai yang kompeten dalam pekerjaan dapat diartikan pegawai tersebut mampu dalam memnjalankan tugas dan tanggung jawab dalam membantu wajib pajak menyelesaikan kewajiban perpajakan dengan baik." (Antwi, 2012).

\section{TINJAUAN PUSTAKA}


Akuntansi Pajak. Dalam menetapkan besar pajak terutang tetap didasarkan laporan keuangan yang disusun oleh perusahaan, mengingat dalam ketentuan undang-undang perpajakan terdapat aturan-aturan khusus yang berkaitan dengan akuntansi, yaitu masalah konsep transaksi dan peristiwa keuangan, metode pengukuran serta pelaporan yang ditetapkan dengan undang-undang. (Waluyo, 2013)

Pengertian Pajak. Pajak adalah iuran rakyat kepada kas negara berdasarkan undangundang (yang dapat dipaksakan) dengan tidak mendapat jasa timbal balik yang lansung dapat ditunjukan dan yang digunakan untuk membayar pengeluaran umum". (Resmi, 2014)

Modernisasi Sistem Administrasi Perpajakan. Diana Sari (2013), "Modernisasi perpajakan ini dapat diartikan sebagai penggunaan sarana dan prasarana perpajakn yang baru dengan memanfaatkan perkembangan ilmu pengetahuan dan teknologi".

Kompetensi Pegawai Pajak. Wibowo (2013), “Kompetensi adalah suatu kemampuan untuk melaksanakan atau melakukan suatu pekerjaan atau tugas yang dilandasi atas keterampilan dan pengetahuan serta didukung oleh sikap kerja yang dituntut oleh pekerjaan tersebut".

Kepuasan Wajib Pajak. Kepuasan pelanggan merupakan suatu keinginan, harapan dan kebutuhan pelanggan terpenuhi. Suatu pelayanan dinilai memuaskan bila pelayanan tersebut dapat memenuhi kebutuhan dan harapan pelanggan". (Pandiangan Liberti, 2014)

\section{Penelitian Terdahulu}

Tabel 1. Penelitian Terdahulu

\begin{tabular}{|c|c|c|c|c|}
\hline No & Peneliti & Judul & Variabel & Hasil \\
\hline 1 & $\begin{array}{l}\text { Welly Surjono, } \\
2015\end{array}$ & $\begin{array}{lr}\text { "Pengaruh modernisasi } \\
\text { administasi } & \text { perpajakan } \\
\text { terhadap } & \text { kepuasan } \\
\text { wajib pajak pada kantor } & \text { pelayanan } \\
\text { praitama } & \text { pajak } \\
\text { bojonagara" } & \end{array}$ & $\begin{array}{l}\text { 1. Modernisasi } \\
\text { Administrasi } \\
\text { Perpajakan } \\
\text { 2. Kepuasan } \\
\text { Wajib Pajak }\end{array}$ & $\begin{array}{l}\text { Modernisasi } \\
\text { administrasi } \\
\text { perpajakan } \\
\text { berpengaruh } \\
\text { signifikan terhadap } \\
\text { kepuasan wajib } \\
\text { pajak }\end{array}$ \\
\hline 2 & $\begin{array}{l}\text { Ezra Eigita } \\
\text { Vigryana, } \\
2016\end{array}$ & $\begin{array}{l}\text { "Pengaru kompetensi } \\
\text { fiskus dan kualitas } \\
\text { pelayanan terhadap } \\
\text { kepuasan wajib pajak" } \\
\text { (Studi pada kantor } \\
\text { pelayanan pajak } \\
\text { pratama malang utara) }\end{array}$ & $\begin{array}{l}\text { 1. Kompetensi } \\
\text { Fiskus } \\
\text { 2. Kualitas } \\
\text { Pelayanan } \\
\text { 3. Kepuasan } \\
\text { wajib pajak }\end{array}$ & $\begin{array}{l}\text { Kompetensi dan } \\
\text { kualitas pelayanan } \\
\text { berpengaru } \\
\text { signifikan terhadap } \\
\text { kepuasan }\end{array}$ \\
\hline
\end{tabular}

\section{Hipotesis}

$\mathrm{Ha}_{1}=$ Modernisasi sistem administrasi berpengaruh terhadap kepuasan wajib pajak

$\mathrm{Ha}_{2}=$ Kompetensi pegawai pajak berpengaruh terhadap kepuasan

$\mathrm{Ha}_{3}=$ Modernisasi sistem administrasi dan kompetensi pegawai berpengaruh terhadap kepuasan

\section{METODE PENELITIAN}

Jenis dan sumber data. (Sugiyono, 2014) "Data primer merupakan sumber data yang langsung memberikan data kepada pengumpul data".

Sampel dan teknik pengambilan sampel. (Sugiyono, 2014) "Sampel merupakan bagian dari jumlah dan karakteristik yang dimiliki populasi. Teknik pengambilan sampel dilakukan dengan teknik sampling insidental". 
Metode analisis. (Sugiyono, 2014) "Kuantitatif yaitu bentuk analisa data berupa angka-angka menggunakan perhitungan statistik untuk menganalisis suatu hipotesis".

Uji Kualitas Data

1. Validitas

2. Reliabilitas

\section{Uji Asusmsi Klasik}

1. Normalitas

2. Multikolinieritas

3. Heteroskedastisitas

Uji Hipotesis. "Analisis regresi bertujuan untuk mengukur kekuatan hubungan antara dua variabel atau lebih serta menunjukan arah hubungan variabel dependen dan independen".(Gozali, 2013).

1. Uji Signifikan statistik t

2. Uji Signifikan Statistik $f$

3. Koefisien Determinasi $\mathrm{r}$

$$
\mathrm{Y}=\alpha+\beta_{1} \mathrm{X}_{1}+\beta_{2} \mathrm{X}_{2}+\varepsilon
$$

Keterangan :

$\mathrm{Y}=$ Kepuasan

$\alpha=$ Konstanta

$\beta_{1} \beta_{2}=$ Koefisien Regresi

$\mathrm{X}_{1}=$ Modernisasi

$\mathrm{X}_{2}=$ Kompetensi

$\varepsilon=$ Error

4. HASIL ANALISIS DAN PEMBAHASAN

4.1. Hasil Analisis

Uji kualitas Data

Validitas

Tabel 2. Validitas $\left(\mathbf{X}_{1}\right)$

\begin{tabular}{|c|c|c|c|}
\hline \multirow[t]{2}{*}{ Pernyataan } & \multicolumn{2}{|c|}{ Korelasi } & \multirow{2}{*}{$\begin{array}{l}\text { Penilaian } \\
\text { V = Valid }\end{array}$} \\
\hline & $\mathbf{R}_{\text {hitung }}$ & $\mathbf{R}_{\text {tabel }}$ & \\
\hline MSA1 & 0,216 & 0,1966 & $\mathrm{~V}$ \\
\hline MSA2 & 0,218 & 0,1966 & V \\
\hline MSA3 & 0,241 & 0,1966 & V \\
\hline MSA4 & 0,213 & 0,1966 & V \\
\hline MSA5 & 0,347 & 0,1966 & V \\
\hline MSA6 & 0,246 & 0,1966 & V \\
\hline MSA7 & 0,301 & 0,1966 & V \\
\hline MSA8 & 0,475 & 0,1966 & V \\
\hline MSA9 & 0,234 & 0,1966 & V \\
\hline MSA10 & 0,201 & 0,1966 & V \\
\hline MSA11 & 0,257 & 0,1966 & V \\
\hline MSA12 & 0.277 & 0,1966 & V \\
\hline MSA13 & 0,302 & 0,1966 & V \\
\hline MSA14 & 0,248 & 0,1966 & V \\
\hline MSA15 & 0,252 & 0,1966 & V \\
\hline MSA16 & 0,306 & 0,1966 & V \\
\hline MSA17 & 0,296 & 0,1966 & V \\
\hline MSA18 & 0,298 & 0,1966 & V \\
\hline MSA19 & 0,326 & 0,1966 & V \\
\hline
\end{tabular}


Pada Tabel 2 seluruh butir pernyataan variabel $\mathrm{X}_{1}$, valid.

Tabel 3. Validitas $\left(\mathbf{X}_{2}\right)$

\begin{tabular}{|c|c|c|c|}
\hline \multirow[t]{2}{*}{ Pernyataan } & \multicolumn{2}{|c|}{ Korelasi } & \multirow{2}{*}{$\begin{array}{l}\text { Penilaian } \\
\text { V = Valid }\end{array}$} \\
\hline & $\mathbf{R}_{\text {hitung }}$ & $\mathbf{R}_{\text {tabel }}$ & \\
\hline KP1 & 0,322 & 0,1966 & V \\
\hline KP2 & 0,246 & 0,1966 & V \\
\hline KP3 & 0,250 & 0,1966 & V \\
\hline KP4 & 0,438 & 0,1966 & V \\
\hline KP5 & 0,258 & 0,1966 & V \\
\hline KP6 & 0,276 & 0,1966 & V \\
\hline KP7 & 0,212 & 0,1966 & V \\
\hline KP8 & 0,226 & 0,1966 & V \\
\hline KP9 & 0,415 & 0,1966 & V \\
\hline KP10 & 0,334 & 0,1966 & V \\
\hline KP11 & 0,338 & 0,1966 & V \\
\hline KP12 & 0,216 & 0,1966 & V \\
\hline KP13 & 0,282 & 0,1966 & V \\
\hline KP14 & 0,372 & 0,1966 & $\mathrm{~V}$ \\
\hline
\end{tabular}

Pada Tabel 3 butiran pernyataan variabel $\mathrm{X}_{2}$, valid.

Tabel 4. Validitas (Y)

\begin{tabular}{cccc}
\hline Pernyataan & \multicolumn{2}{c}{ Korelasi } & Penilaian \\
\cline { 2 - 3 } & $\mathbf{R}_{\text {hitung }}$ & $\mathbf{R}_{\text {tabel }}$ & Valid \\
\hline KWP1 & 0,315 & 0,1966 & V \\
KWP2 & 0,270 & 0,1966 & V \\
KWP3 & 0,203 & 0,1966 & V \\
KWP4 & 0,267 & 0,1966 & V \\
KWP5 & 0,256 & 0,1966 & V \\
KWP6 & 0,201 & 0,1966 & V \\
KWP7 & 0,327 & 0,1966 & V \\
KWP8 & 0,407 & 0,1966 & V \\
KWP9 & 0,241 & 0,1966 & V \\
KWP10 & 0,222 & 0,1966 & V \\
KWP11 & 0,332 & 0,1966 & V \\
KWP12 & 0,256 & 0,1966 & V \\
KWP13 & 0,273 & 0,1966 & V \\
KWP14 & 0,227 & 0,1966 & V \\
KWP15 & 0,220 & 0,1966 & V \\
KWP16 & 0,214 & 0,1966 & V \\
KWP17 & 0,233 & 0,1966 & V \\
KWP18 & 0,304 & 0,1966 & \\
KWP19 & 0,212 & 0,1966 & \\
\hline
\end{tabular}

Pada Tabel 4 butir pernyataan variabel Y, valid. 


\section{Reliabilitas}

Tabel 5. Reliabilitas

\begin{tabular}{llccc}
\hline No & \multicolumn{1}{c}{ Variabel } & Nilai alpha & $\mathbf{R}_{\text {hitung }}$ & Keterangan \\
\hline 1 & Modernisasi Sistem & 0,287 & 0,1966 & Reliabel \\
& Administrasi Perpajakan & & & \\
2 & Kompetensi Pegawai & 0,219 & 0,1966 & Reliabel \\
3 & Kepuasan Wajib Pajak & 0,207 & 0,1966 & Reliabel \\
\hline
\end{tabular}

Pada Tabel 5 seluruh item pernyataan reliabel

\section{Hasil Uji Asumsi Klasik Normalitas}

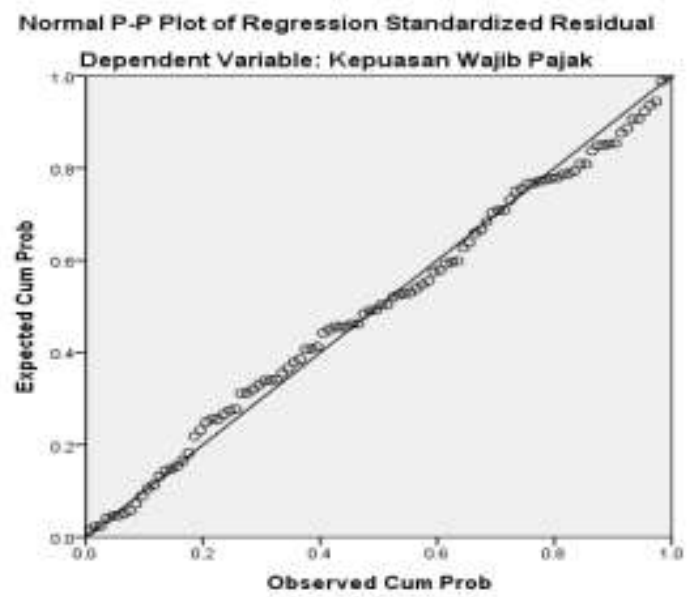

Gambar 1. Normalitas

Gambar 1 Menunjukan regresi memenuhi asumsi normalitas

Multikolinearitas

Tabel 6. Multikolinearitas

\begin{tabular}{|c|c|c|c|c|c|c|c|}
\hline \multirow[b]{2}{*}{ Model } & \multicolumn{2}{|c|}{$\begin{array}{l}\text { Unstandardized } \\
\text { Coefficients }\end{array}$} & \multirow{2}{*}{$\begin{array}{c}\begin{array}{c}\text { Standardized } \\
\text { Coefficients }\end{array} \\
\text { Beta }\end{array}$} & \multirow[b]{2}{*}{$\mathrm{t}$} & \multirow[b]{2}{*}{ Sig. } & \multicolumn{2}{|c|}{$\begin{array}{l}\text { Collinearity } \\
\text { Statistics }\end{array}$} \\
\hline & $\mathrm{B}$ & Std. Error & & & & Tolerance & VIF \\
\hline (Constant) & 9.635 & 2.621 & & 3.676 & .000 & & \\
\hline $\begin{array}{l}\text { Modernisasi Sistem } \\
\text { Administrasi Perpajakan }\end{array}$ & .695 & .047 & .778 & 14.773 & .000 & .759 & 1.317 \\
\hline Kompetensi Pegawai Pajak & .212 & .056 & .198 & 3.768 & .000 & .759 & 1.317 \\
\hline
\end{tabular}

a. Dependent Variable: Kepuasan Wajib Pajak

Pada Tabel 6 dilihat VIF variabel independen $\mathrm{X}_{1} 1,317$ dan variabel independen $\mathrm{X}_{2}$ 1,317 keduanya $<10,00$ sedangkan dari tolerance variabel indepenen $X_{1} 0,759$ dan variabel indepen $\mathrm{X}_{2}$ 0,759 keduanya $>0,10$. Ini menunjukan tidak terjadi multikolinearitas. 


\section{Heteroskedastisitas}

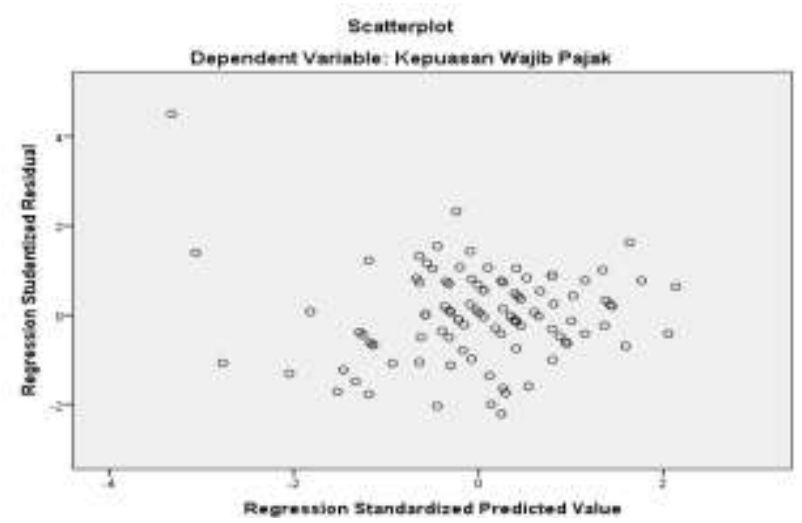

Gambar 2. Heteroskedastisitas

Pada Gambar 2 dilihat tidak terjadi heteroskedastisitas pada model regresi.

\section{Hasil Uji Hipotesis Uji Signifikan $t$}

Tabel 7. Uji Signifikan t

\begin{tabular}{|c|c|c|c|c|c|c|}
\hline & & Unstand & d Coefficients & $\begin{array}{l}\text { Standardized } \\
\text { Coefficients }\end{array}$ & & \\
\hline & Model & $\mathrm{B}$ & Std. Error & Beta & $\mathrm{t}$ & Sig. \\
\hline 1 & (Constant) & 9.635 & 2.621 & & 3.676 & .000 \\
\hline & $\begin{array}{l}\text { Modernisasi Sistem } \\
\text { Administrasi Perpajakan }\end{array}$ & .695 & .047 & .778 & 14.773 & .000 \\
\hline & Kompetensi Pegawai Pajak & .212 & .056 & 198 & 3.768 & .000 \\
\hline
\end{tabular}

\section{Uji Signifikan $\mathbf{f}$}

Tabel 8. Uji Signifikan f

\begin{tabular}{llccccc}
\hline & Model & Sum of Squares & df & Mean Square & $\mathrm{F}$ & Sig. \\
\hline 1 & Regression & 1083.677 & 2 & 541.839 & 188.982 & $.000^{\mathrm{b}}$ \\
& Residual & 278.113 & 97 & 2.867 & & \\
& Total & 1361.790 & 99 & & & \\
\hline
\end{tabular}

a. Dependent Variable: Kepuasan Wajib Pajak

b. Predictors: (Constant), Kompetensi Pegawai Pajak, Modernisasi Sistem Administrasi Perpajakan

\section{Uji Koefisien Determinasi}

\section{Tabel 9. Koefisien Determinasi}

\begin{tabular}{ccccc}
\hline Model & $\mathrm{R}$ & $\mathrm{R}$ Square & Adjusted R Square & Std. Error of the Estimate \\
\hline 1 & $.892^{\mathrm{a}}$ & .796 & .792 & 1.69326
\end{tabular}

a. Predictors: (Constant), Kompetensi Pegawai Pajak, Modernisasi Sistem Administrasi Perpajakan

b. Dependent Variable: Kepuasan Wajib Pajak

\subsection{Pembahasan}

Uji hipotesis Ha. Dari hasil Tabel 7 nilai $t_{\text {hitung }}$ untuk variabel independen $\mathrm{X}_{1}$ 14,773 dengan tingkat signifikan 0,000. Karena nilai $t_{\text {hitung }} 14,773>t_{\text {tabel }}$ 1,660 dan nilai signifikan $0,000<0,05$. Maka $\mathrm{H}_{0}$ ditolak dan $\mathrm{Ha}_{1}$ diterima. Bisa dikatakan variabel $\mathrm{X}_{1}$ berpengaruh signifikan terhadap variabel dependen $(\mathrm{Y})$.

Uji Hipotesis Ha $\mathbf{H}_{2}$. Untuk variabel bebas kedua hasil yang telah ditunjukan pada tabel

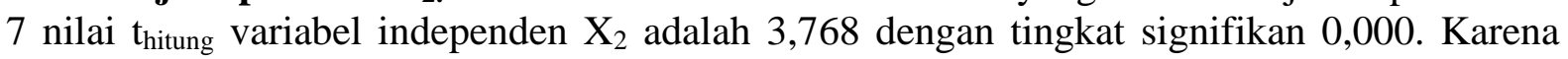
nilai $\mathrm{t}_{\text {hitung }} 3,768>\mathrm{t}_{\text {tabel }} 1,660$ dan tingkat signifikan $0,000<0,05$, maka $\mathrm{H}_{0}$ ditolak dan 
menerima $\mathrm{Ha}_{2}$, Dapat dikatakan variabel independen $\mathrm{X}_{2}$ berpengaruh signifikan terhadap variabel dependen Y.

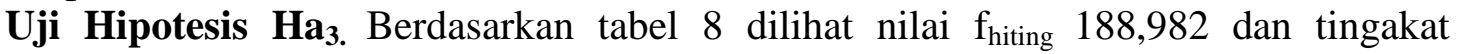
signifikan 0,000. Kerana $\mathrm{f}_{\text {hitung }} 188,982>$ dari $\mathrm{f}_{\text {tabel }} 3,09$. Berarti variabel indepen bersamaan berpengaruh signifikan terhadap variabel dependen $\mathrm{Y}$.

Uji Koefisien Determinasi. Berdasarkan Tabel 9 nilai $r$ dihasilkan 0,892 atau 89,2\% artinya mempunyai hubungan yang kuat. Nilai R Square 0,796 ini mengandung arti pengaruh variabel independen terhadap dependen ialah 79,6\% sisanya $24,4 \%$ dipengaruhi variabel lain.

\section{KESIMPULAN DAN SARAN}

\subsection{Kesimpulan}

1. Semua variabel independen sma-sama berpengaruh signifikan terhadap variabel dependen.

2. Variabel independen secara parsial berpengaruh terhadap variabel dependen.

\subsection{Saran}

Mengingat masing-masing variabel berpengaruh signifikan serta memberikan kontribusi yang cukup besar, maka sebaiknya para pegawai dan semua pihak yang terkait harus lebih memperhatikan faktor sistem administrasi dan kompetansi pegawai.

\section{DAFTAR PUSTAKA}

Antwi, S., E. F. E. A. Mills, X, Zhao. 2012. Capital structure and firm value: empirical Evidance From Ghana. International journal of business and social science 3(22): $103-111$.

Diana sari, 2013. Konsep dasar perpajakan. Bandung: Refika Aditama.

Direktorat Jenderal Pajak, 2007. Himpunan perubahan undang-undang perpajakan. Financial Accounting standard Nomor. 66. 1982, Nomor 67, 1982. Stanfod. FASB.

Ezra Eigita Vigryana, 2016. Pengaruh kompetensi fiskus dan kualitas pelayanan terhadap kepuasan wajib pajaka (studi pada kantor pelayanan pajak pratama malang utara). PS Perpajakan, Jurusan Administrasi bisnis, Universitas Brawijaya. Malang, Indonesia.

Gozali, 2013. Aplikasi Analisis Multivarite Dengan program SPSS. Edisi Ketujuh. Semarang: Badan Penerbit Unifersitas Diponegoro.

Indra Pahala dkk, 2013. Pengaruh kompetensi pegawai pajak dan kualitas pelayanan pajak pada kantor pelayanan pajak pratama jakarta koja. Prosiding Simposium Nasional Perpajakan 4.

Pandiangan Liberti, 2014. Administrasi Perpajakan, Penerbit Erlangga.

Sugiyono, 2014. Metode Penelitian Pendidikan Pendekatan Kuantitatif, Kualitatif, dan R\&D. Bandung: ALFABETA

Waluyo, 2013. Perpajakan Indonesia, Edisi Refisi, Salemba Empat, Jakarta.

Welly Surjono, 2015. Pengaruh modernisasi administrasi perpajakan terhadap kepuasan wajib pajak pada kantor pelayanan pajak pratama bandung bojonagara. Akuntansi, Fakultas Ekonimi Universitas Sangga Buana YPKP, Bandung.

Wibowo, 2013. Pemahaman Praktis Manajemen Sumber Daya Manusia. Bandung: Mandar Maju.

Resmi, 2014. Perpajakan Teori Dan Kasus Edisi 7 Buku 1. Salemba Empat, Jakarta. 